\title{
Initial outcomes of using allografts from donation after cardiac death donors for liver transplantation in New South Wales
}

\section{Jorieke M van der Stelt Medical Student \\ Deborah J Verran MB ChB, FRACS, Transplant Surgeon ${ }^{2}$ \\ Ronald A deRoo \\ Transplant Fellow ${ }^{2}$ \\ Hazel Christine \\ State Organ Donor \\ Co-ordinator $^{3}$ \\ Michael Crawford \\ MB BS, FRACS, \\ Surgeon ${ }^{2}$ \\ 1University of Groningen, Groningen, Netherlands. \\ 2 Royal Prince \\ Alfred Hospital, \\ Sydney, NSW. \\ 3 NSW Organ and Tissue \\ Donation Service \\ Sydney, NSW.}

verran@ausdoctors.net

MJA 2013; 199: 104-106 doi: 10.5694/mjal2.11465

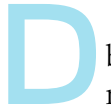

espite liver transplantation being an established treatment modality in Australia, there continues to be a significant disparity between donor liver availability and demand. ${ }^{1}$ One way to reduce this gap is to maximise the use of extendedcriteria deceased donor livers, with donation after cardiac death (DCD) being one such option. ${ }^{2}$ However, the additional warm ischaemia time (WIT) incurred during the DCD donation process has led to a higher reported incidence of complications. ${ }^{3,4}$

Until recently, all deceased donor liver transplants in Australia were performed with liver allografts retrieved from donors after brain death. However, prior to brain death legislation being established within all jurisdictions, all the early experience in deceased donor organ transplantation was done solely with DCD renal allografts. ${ }^{5}$ In New South Wales in the 1980s, when transplantation of the other solid organs became a reality with donation after brain death, the practice of DCD renal transplantation all but ceased. All the preliminary experience with liver transplantation in Europe and the United States was with the use of DCD liver allografts, ${ }^{6,7}$ but the focus switched to donation after brain death after the recognition of brain death as an entity and the enactment of legislation.

With controlled DCD organ donation becoming re-established internationally in the $1990 \mathrm{~s},{ }^{8-10}$ reports then emerged of reasonable outcomes in renal followed by liver and then lung transplantation. ${ }^{11-14}$ Hence, interest was rekindled in NSW with respect to the DCD pathway for organ donation. This culminated in the release of a jurisdictional policy guideline document by NSW Health in 2007, which also facilitated the development of

\begin{abstract}
Objectives: To report the early outcomes of the initial selection and use of donation after cardiac death (DCD) donor livers for transplantation in New South Wales, following a guidelines implementation process.

Design and setting: Review of database and medical records from the Australian National Liver Transplantation Unit and the NSW Organ and Tissue Donation Service for DCD activity including organ donor offers and retrievals, from 1 July 2007 to 31 December 2010.

Main outcome measures: Acceptance and utilisation rates of livers from DCD donors, and patient and graft outcomes after liver transplantation.

Results: Of the potential 84 DCD donor offers, 45 were declined, and 15 of the 39 attempted retrievals provided livers for transplantation. The most common reason for non-retrieval of the liver was the time to declaration of death exceeding 30 minutes after withdrawal of treatment (14 donors), followed by abnormality in the donor liver (eight donors). Data on early outcomes for liver transplant recipients showed a median peak aspartate aminotransferase of $3667 \mathrm{U} / \mathrm{L}$ (range, 919-11264 U/L), but no delayed graft function. Four patients developed biliary complications (two within 3 months and two later). Patient and graft survival were $100 \%$ at a median follow-up of 15 months.

Conclusions: As a result of the re-establishment of multiorgan donation through the DCD pathway, 15 (18\%) of the selected DCD donors provided livers for transplantation. Patient and graft survival rates were excellent, and the rate of intra- and postoperative complications was acceptable. Hence, the selective transplantation of DCD donor liver allografts will continue to be pursued and the outcomes followed.
\end{abstract}

collaborative multiorgan retrieval surgical protocols between the Australian National Liver Transplantation Unit (ANLTU) and the regional lung transplant unit for DCD donors. ${ }^{15}$

\section{Methods}

Data collected prospectively from 1 July 2007 to 31 December 2010 were analysed. Donor data were obtained from the NSW Organ and Tissue Donation Service, while data on the acceptance and utilisation of the DCD livers for transplantation were obtained from the ANLTU database. Patient and graft outcomes data were also obtained from the ANLTU database, as well as hospital records, with a minimum of 6 months' recipient follow-up. The study was approved by the South Eastern Sydney and Illawarra Area Health Service and Syd- ney South West Area Health Service ethics review panels. Statistical analysis was performed with StatsDirect version 2.7.8 (StatsDirect).

\section{ANLTU protocol for liver retrieval from $D C D$ donors}

The ANLTU protocol based on international best practice is outlined in the Appendix (online at mja.com.au). ${ }^{15-18}$

\section{Selection of recipients}

Before listing, all potential liver transplant recipients were evaluated by a multidisciplinary liver transplant team. Informed consent about the possibility of the use of a DCD liver allograft was obtained. Patients were accepted onto the liver transplant waiting list in accordance with the Transplantation Society of Australia and New Zealand consensus statement protocols. ${ }^{19}$ Donor livers were preferentially allocated to recipients in 
1 Rates of acceptance of and livers retrieved from donation after cardiac death donors

\begin{tabular}{cccc} 
Year & $\begin{array}{c}\text { Donor } \\
\text { offers }\end{array}$ & $\begin{array}{c}\text { Non-acceptance of offer for } \\
\text { liver transplantation }\end{array}$ & $\begin{array}{c}\text { Livers retrieved for transplantation/ } \\
\text { potential suitable donors }\end{array}$ \\
\hline 2007 & 6 & 5 & $1 / 1$ \\
2008 & 16 & 8 & $2 / 8$ \\
2009 & 26 & 14 & $4 / 12$ \\
2010 & 36 & 18 & $8 / 18$ \\
\hline
\end{tabular}

whom the surgical hepatectomy was expected to be straightforward, in an attempt to limit the cold ischaemia time of the donor liver to less than 8 hours. $^{14}$

\section{Liver transplant process}

Liver transplantation was performed with standard operative techniques. A routine postimplantation postreperfusion biopsy sample of the liver was obtained for histological testing, including the grading of steatosis. ${ }^{20}$ Recipients were managed postoperatively according to ANLTU protocols.

\section{Outcome measures}

Data on the donors included donor demographics, underlying cause of death, and the outcomes of the donation and surgical retrieval process. Data on early outcomes (within the first 3 months) were obtained for 14 of the transplanted livers. This included liver allograft function and recipient intraoperative and postoperative course (including biliary and vascular complications). Late outcome data included significant recipient complications as well as recipient and graft survival. Primary non-function and initial poor graft function were defined according to previous publications. ${ }^{20}$

\section{Results}

\section{Acceptance of donor offers for liver transplantation by the transplant team}

The number of DCD offers steadily increased over the first 3.5 years as seen in Box 1, with acceptance rates being relatively consistent after the first year. Forty-five of 84 donor offers were not accepted mostly because the donor parameters fell outside of the ANLTU DCD acceptance criteria. The most common reason for nonacceptance was advanced donor age alone (21/45), followed by medical abnormalities combined with advanced donor age (12/45), isolated medical abnormalities (8/45), and other factors (4/45), including organisational logistics and withdrawal of consent for donation. However, thirty-five of these 45 potential DCD donors subsequently provided other organs for transplantation.

\section{Outcomes of the planned DCD surgical retrieval}

Surgical retrieval teams travelled to donor hospitals of 39 potential DCD donors during the study period. The liver was successfully retrieved for subsequent transplantation in 15 of these donors. There was no difference in demographics between the donors where the liver was successfully able to be retrieved and the donors where it was not. The median $\gamma$-glutamyl transpeptidase level was higher in the donors where the liver was not retrieved $(81 \mathrm{IU} / \mathrm{L})$ compared with the donors where it was retrieved (47IU/L).

For the DCD donors where the liver was successfully retrieved, the location of the potential donor at the time of withdrawal of treatment was within the intensive care unit (ICU) in 12 donors, and in the operating theatre complex for the remaining three. The median time from withdrawal of treatment to declaration of death was
11 minutes (range, 4-19 minutes). The subsequent median WIT was 26 minutes (range, 17-35 minutes). The most common reason for nonretrieval of the liver was that death did not occur within the predetermined time frame of less than 30 minutes (14/24 donors), followed by an abnormality detected in the donor liver (8/24 donors) and unforeseen issues with logistics (2/24 donors). Of the 39 donors where liver retrieval was attempted, 25 provided other organs for transplantation.

\section{Outcomes of DCD liver transplants}

There were 13 adult and one paediatric recipients, with a median age of 57 years (range, 4-63 years). One donor liver was not used. All the recipients underwent primary liver transplantation. The paediatric recipient received an urgent transplant with a cutdown of a DCD donor liver. The underlying primary liver diseases were hepatitis $\mathrm{C}$ virus (six patients), postalcoholic cirrhosis (four patients), hepatocellular carcinoma (three patients) and fulminant hepatic failure (one patient). At the time when a potential donor was identified, 11 recipients were at home, two were hospitalised and the paediatric recipient was in the ICU. The median cold ischaemia time was 7.7 hours (range, 4.9-9.7 hours). The patient and graft outcomes are shown in Box 2, with a median patient follow-up period of 14.8 months (range, 4-39 months).

The early outcomes were favourable, with no primary non-function or significant initial poor graft function despite the peak serum aspartate aminotransferase levels. This was despite five allografts having moderate isolated microvesicular steatosis on

\begin{tabular}{|c|c|c|}
\hline Outcome & $\begin{array}{l}<3 \text { months } \\
\text { after transplant }\end{array}$ & $\begin{array}{l}>3 \text { months } \\
\text { after transplant }\end{array}$ \\
\hline \multicolumn{3}{|l|}{ Early graft function } \\
\hline Median peak AST level (range) & 3667IU/L (919-11264IU/L) & \\
\hline Median AST level on Day 3 (range) & $371 \mathrm{IU} / \mathrm{L}(92-1375 \mathrm{IU} / \mathrm{L})$ & \\
\hline \multicolumn{3}{|l|}{ Biliary complications } \\
\hline Bile leak & $1 / 14$ & - \\
\hline Anastomotic stricture & $1 / 14$ & $2 / 14$ \\
\hline \multicolumn{3}{|l|}{ Vascular complications } \\
\hline Portal vein thrombosis & $1 / 14$ & - \\
\hline Hepatic artery stenosis & $1 / 14$ & - \\
\hline
\end{tabular}


postreperfusion biopsy and one having moderate macrovesicular steatosis. The two vascular complications occurred within the first 3 months, and the hepatic artery stenosis was managed with percutaneous balloon dilatation on two occasions. The one case of early bile leak necessitated reoperation and revision of the biliary anastomosis. An anastomotic stricture of the Roux-en-Y was then diagnosed 3 months later, and corrected through endoscopic management (dilatation). The one patient with an early anastomotic biliary stricture underwent endoscopic retrograde cholangiopancreatography (ERCP) and stenting.

The two patients with anastomotic biliary stricture after 3 months required ERCP and stenting. For both patients, multiple ERCPs and stent changes have been required. In one patient there was also biliary sludge and stone formation. One of these two patients required no further stents after 13 months.

\section{Discussion}

Since the re-establishment of organ donation through the DCD pathway in NSW, it has become possible to undertake liver transplantation with liver allografts from DCD donors. However, the relatively high rate of non-acceptance of DCD liver offers during the study period reflects the ANLTU acceptance criteria, which are based on known outcomes of DCD liver transplantation internationally. ${ }^{4,21,22}$

The high percentage of attempted donor retrievals resulting either in non-retrieval or discarding of the liver is consistent with the nature of the DCD process; additionally, in potential donors, death must occur within a short time frame such that the resulting WIT is less than 30 minutes. ${ }^{3,14}$ The number of liver allografts discarded at the time of retrieval because of steatosis or perfusion abnormality is also consistent with other reported experience. $^{12}$
The liver allograft outcomes are consistent with other reports including for the rate of biliary complications. ${ }^{23}$ Although ischaemic cholangiopathy was not seen in this small series, this may reflect both the short follow-up period and the relatively small number of cases compared with other reported series. ${ }^{3}$ The increased incidence of vascular complications including hepatic artery stenosis, ${ }^{23}$ along with the increased requirement for retransplantation, was not seen in this initial experience with DCD liver allografts. ${ }^{22}$

As the results from the initial experience with the use of liver allografts from DCD donors have proven to be favourable, the ANLTU has made a decision to raise the upper age limit for potential donors to 50 years. As the utility of DCD organ donation remains limited, with only $18 \%$ of the donors providing liver allografts, the more common practice of obtaining liver allografts through donation after brain death appears to be a more resource-efficient option.

\section{Competing interests: No relevant disclosures.}

Received 26 Sep 2012, accepted 5 May 2013.

1 Prakoso E, Verran D, Dilworth P, et al. Increasing liver transplantation waiting list mortality: a report from the Australian National Liver Transplantation Unit, Sydney. Intern Med J 2010; 40: 619-625.

2 Durand F, Renz JF, Alkofer B, et al. Report of the Paris consensus meeting on expanded criteria donors in liver transplantation. Liver Transpl 2008; 14: 1694-1707.

3 Jay CL, Lyuksemburg V, Ladner DP, et al. Ischemic cholangiopathy after controlled donation after cardiac death liver transplantation: a metaanalysis. Ann Surg 2011; 253: 259-264.

4 Abt P, Crawford M, Desai N, et al. Liver transplantation from controlled non-heartbeating donors: an increased incidence of biliary complications. Transplantation 2003; 75: 16591663.

5 Sheil AG, Stewart JH, Johnson JR, et al. Community treatment of end-stage renal failure by dialysis and renal transplantation from cadaver donors. Lancet 1969; 2: 917-920.

6 Calne RY. Early days of liver transplantation. Am J Transplant 2008; 8: 1775-1778.

7 Yamamoto S, Wilczek HE, Duraj FF, et al. Liver transplantation with grafts from controlled donors after cardiac death: a 20-year follow-up at a single center. Am J Transplant 2010; 10: 602-611.
8 D’Alessandro AM, Hoffmann RM, Knechtle SJ et al. Controlled non-heart-beating donors: a potential source of extrarenal organs. Transplant Proc 1995; 27: 707-709.

9 Reich DJ, Munoz SJ, Rothstein KD, et al. Controlled non-heart-beating donor liver transplantation: a successful single center experience, with topic update. Transplantation 2000; 70: 1159-1166.

10 Kootstra G, Daemen JH, Oomen AP. Categories of non-heart-beating donors. Transplant Proc 1995; 27: 2893-2894.

11 Cooper JT, Chin LT, Krieger NR, et al. Donation after cardiac death: the University of Wisconsin experience with renal transplantation. Am J Transplant 2004; 4: 1490-1494.

12 Muiesan P, Girlanda R, Jassem W, et al. Singlecenter experience with liver transplantation from controlled non-heartbeating donors: a viable source of grafts. Ann Surg 2005; 242: 732-738.

13 Domínguez-Gil B, Haase-Kromwijk B, Van Leiden $\mathrm{H}$, et al. Current situation of donation after circulatory death in European countries. Transpl Int 2011; 24: 676-686.

14 Bernat JL, D’Alessandro AM, Port FK, et al. Report of a National Conference on Donation after cardiac death. Am J Transplant 2006; 6: 281-291.

15 NSW Health. Organ donation after cardiac death: NSW guidelines. Sydney: NSW Health, 2011. http://www.health.nsw.gov.au/policies/gl/2011/ GL2011_005.html (accessed Jul 2012).

16 Reich DJ, Mulligan DC, Abt PL, et al. ASTS recommended practice guidelines for controlled donation after cardiac death organ procurement and transplantation. Am J Transplant 2009; 9: 2004-2011.

17 Hashimoto K, Eghtesad B, Gunasekaran G, et al. Use of tissue plasminogen activator in liver transplantation from donation after cardiac death donors. Am J Transplant 2010; 10: 2665-2672.

18 Hong JC, Yersiz H, Kasitamongkol P, et al. Liver transplantation using organ donation after cardiac death: a clinical predictive index for graft failure-free survival. Arch Surg 2011; 146: 1017 1023.

19 The Transplantation Society of Australia and New Zealand. Organ transplantation from deceased donors: consensus statement on eligibility criteria and allocation protocols. Version 1.1. 23 June 2011. http://www.tsanz.com. au/organallocationprotocols/index.asp (accessed Jul 2012).

20 de Graaf EL, Kench J, Dilworth P, et al. Grade of deceased donor liver macrovesicular steatosis impacts graft and recipient outcomes more than the Donor Risk Index. J Gastroenterol Hepatol 2012; 27: 540-546.

21 Lee KW, Simpkins CE, Montgomery RA, et al. Factors affecting graft survival after liver transplantation from donation after cardiac death donors. Transplantation 2006; 82 1683-1688.

22 Abt PL, Desai NM, Crawford MD, et al. Survival following liver transplantation from non-heartbeating donors. Ann Surg 2004; 239: 87-92.

23 Foley DP, Fernandez LA, Leverson G, et al. Biliary complications after liver transplantation from donation after cardiac death donors: an analysis of risk factors and long-term outcomes from a single center. Ann Surg 2011; 253: 817-825. 